\title{
Structural Engineering Perspective for a Novel Ion Exchange Membrane
}

\author{
Jaewon Jang* \\ School of Earth Sciences and Environmental Engineering (SESE), Gwangju Institute of Science and Technology, Republic of Korea
}

Submission: May 19, 2021; Published: May 24, 2021

*Corresponding author: Jaewon Jang, School of Earth Sciences and Environmental Engineering (SESE), Gwangju Institute of Science and Technology, Republic of Korea

\section{Abstract}

Most of the studies about ion exchange membrane (IEM) have been focused on the analysis of commercial IEM, material engineering on the tailor-made membrane, and system engineering related to the IEM applications. However, the structural engineering of IEM is quite effective to improve drastically IEM properties because the structure can affect the movement and hindrance of ion in the membrane body. It is worth taking this opportunity to recall the need for IEM structural studies. As one idea of structural engineering research, an IEM that simulates the concrete structure of a building can be very effective to overcome the limitation of conventional IEMs.

Keywords: Ion exchange membrane; structural engineering; nanofiber; concrete; composite

\section{Introduction}

The role of IEM is quite important in various research or industrial area, but its development has been stagnant in recent years. At this point, attempts to fabricate IEMs using a wider range of material are needed, but improving performance with this approach is nearing the limit so that it is necessary to think more fundamental engineering. The most important point that limits the performance of conventional IEMs is the nanostructure of membrane. It is difficult to obtain great effects in electrochemical applications that require smooth transport of ions since the conventional IEMs have a nanostructure that interferes with the movement of ions. The number of papers dealing with IEM related to the electrochemical application is increasing (Figure 1a), but the most of studies were still focused on electrode part or electrochemical system [1]. And, the studies of physical/chemical properties using commercial IEMs or well-known tailor-made IEMs were also intensively conducted. Only a few research focused on the IEM structure even though structural engineering is a quite effective way to overcome the limitation of IEM property for electrochemical applications (Figure 1b) [1]. Among the studies related to IEM structure, very a few studies reported a drastic change of the entire membrane structure, and most of them are the results that introducing nanopores or channels in the IEM. Therefore, we need to consider more fundamental and innovative ideas based on a clear understanding of the IEMs.

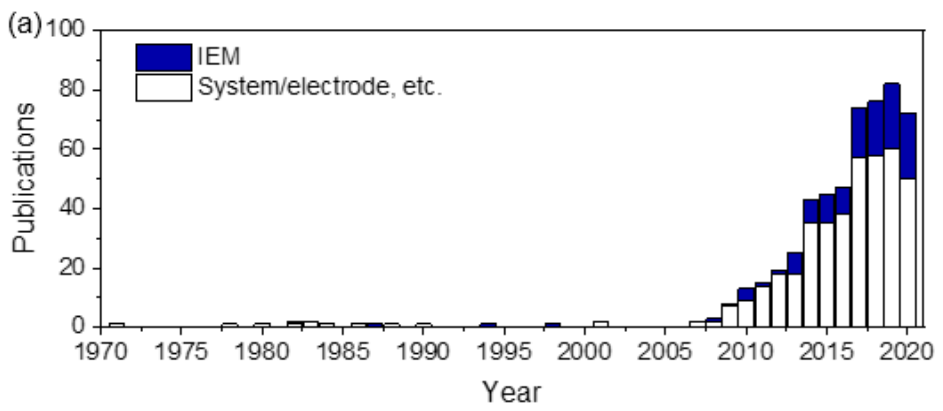

(b)

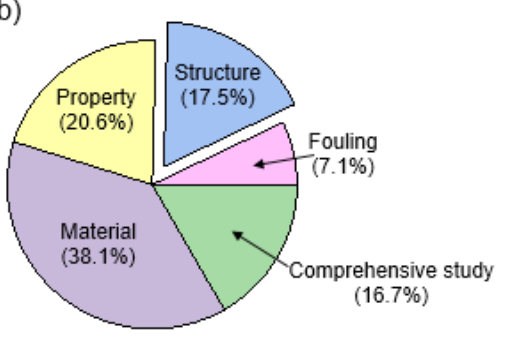

Figure 1: (a) The number of papers related to the IEM in electrochemical applications, (b) The content ratio of the IEM papers (Survey in Scopus). 


\section{Suggestion for developing a novel ion exchange membrane}

To overcome the technical limitations of previous IEMs, it is necessary not only to find novel materials but also to structurally modify the IEM. The layered membrane or a thick mixture of resin and polymer were intensively used in various fields because mechanical strength is prioritized in conventional IEMs. In advanced forms, filling porous support or mesh-shaped spacer with an electrolyte having ion exchange properties has been tried. These IEMs can show improved areal resistance and permselectivity, but these are not suitable because the resistance in the system was increased when stacking many IEMs which resulted from the hindering effect against ions. Therefore, the most ideal structure is that the membrane is thin and there is no support layer. If the mechanical strength of membrane is severely degraded without support, making open-structured support can be an option. By considering the above-mentioned issues, I suggest the concrete-structured membrane inspired by the building. The concrete structure consists of a hard skeleton and filler material, and it can endure stress greater than the capacity of the individual material [2]. Skeleton gives basic strength to the structure and filler acts as a buffer for distributing stress and reducing displacement of the skeleton. Based on this principle, if nanofibers are used as a support and filled with a material having ion exchange property, it can be expected that the movement of ions will be smooth while maintaining the minimum mechanical strength (Figure 2). In addition, it will be easy to modify the overall membrane thickness, unlike the conventional method of forming an ion exchange layer on a support having a predetermined thickness. Moreover, if appropriate nanomaterials which have high Zeta potential are introduced, it is expected that the high ion selectivity can be achieved even the membrane thickness thin.

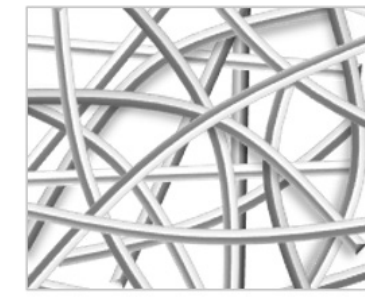

Pristine nanofiber

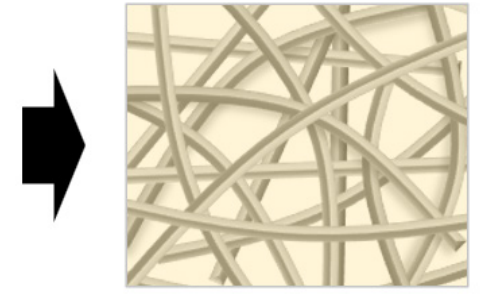

Ionomer-filled nanofiber

Figure 2: Scheme of concrete-structured composite IEM.

\section{Conclusion}

Although structural engineering studies can surprisingly change the properties of IEM, most of the studies have been conducted to analyzing the properties of commercial IEMs or fabricating tailor-made IEMs using new materials. However, the structure of IEM must be studied because it can have a very significant effect on the mobility of ions. One idea proposed in this 'Opinion' is to design an IEM that mimics the concrete structure of a building. It is expected that the mechanical strength of the membrane can be improved without deteriorating the ion exchange properties by making a material which acts as a support in the form of nanofiber and filling it with an ion exchange material.

\section{Acknowledgment}

This work was supported by the GIST Research Project grant funded by the GIST in 2021.

\section{References}

1. Jang J (2020) Cellulose acetate/MXene composite nanofiber-based cation exchange membrane for electrochemical energy generation, Gwangju Institute of Science and Technology, South Korea.

2. (1997) Nonconventional Concrete Technologies: Renewal of the Highway Infrastructure, National Academies Press, Washington, USA. 
This work is licensed under Creative Commons Attribution 4.0 License DOI: 10.19080/AJOP.2021.05.555653
Your next submission with Juniper Publishers will reach you the below assets

- Quality Editorial service

- Swift Peer Review

- Reprints availability

- E-prints Service

- Manuscript Podcast for convenient understanding

- Global attainment for your research

- Manuscript accessibility in different formats

( Pdf, E-pub, Full Text, Audio)

- Unceasing customer service

Track the below URL for one-step submission https://juniperpublishers.com/online-submission.php 